\title{
Rektal Prolapsusa Neden Olmuş Kanser Görüntüsü Olan Dev Villöz Adenom
}

\section{Giant Villous Adenoma Which Appears As a Cancer Cousing Rectal Prolapsus}

Murat Çakır ${ }^{1}$

Mehmet Kılıç²

${ }^{1}$ Necmettin Erbakan Üniversitesi Meram Tıp Fakültesi Genel Cerrahi AD, Konya, Türkiye ${ }^{2}$ Necmettin Erbakan Üniversitesi Meram Tıp Fakültesi Tıbbi Farmakoloji AD, Konya, Türkiye

Geliş Tarihi/Received: 23 Şubat 2017 Kabul Tarihi/Accepted: 10 Temmuz 2017

Yazışma Adresi: Murat Çakır, Necmettin Erbakan Üniversitesi Meram Tıp Fakültesi Genel Cerrahi AD, Konya, Türkiye

e-posta: drmuratcakir@hotmail.com

ORCID

Murat Çakır

https://orcid.org/0000-0001-8789-8199

\begin{abstract}
Öz
Kolorektal kanserlerin büyük çoğunluğu poliplerden gelișir. Beklenmedik bir klinikle ortaya çıkan ve tanıda yanılmaya neden olan karmaşık dev rektal polipli bir olguyu literatür eşliğinde tartışmak istedik. Olgu: Otuz altı yaşında erkek hasta. Yaklaşık 1 yıldır olan kramp tarzı karın ağrısı ve barsak alışkanlığında değişme mevcuttu. Kolonoskopide çekumda malign kitle ve rektumda dev villöz adenom tespit edildi. Cekumdaki kitle laparoskopik cerrahi ile çıkarıldı. Rektumdaki kitleye lokal eksizyonla polipektomi yapıldı. Polipte kanser görülmesine rağmen cerrahi sınır ve kabul edilebilir histolojik özellikler nedeniyle yapılan işlem yeterli kabul edildi. Kolorektal polipler kanser riski taşıyan lezyonlar olduğu için detaylı histopatolojik inceleme yapılmalı ve cerrahi karar titizlikle verilmelidir

Anahtar Kelimeler: Polip, rektum, kanser

\section{Abstract}

Many of the colorectal cancers originated from polips. We wanted to discuss a case accompanied with literature who has a complicated giant rectal polip which presented with an unusual clinic and confusion in diagnosis. 36 years old male patient. He has cramp like stomache and changing in volonic habits for about a year.During colonoscopy a malign mass in caecum and a giant villous adenoma in rectum is identified. The mass in caecum is excised via laparoscopic surgery. The mass in rectum received polipectomy via local excision. Altough a cancer has seen in the polip the surgery is considered opprepriote because of the surgical frontier and acceptable histologic properties. Colorectal polips are lesions which has the risk to turn into cancers thus, detoiled histopatologic examination and gently decission of surgery is needed.
\end{abstract}

Keywords: Polyp, rectum, cancer

\section{GiRiş}

Polip terimi nonspesifik bir terim olup histopatolojik yapısına bakmaksızın intestinal mukoza yüzeyinden lümene doğru çıkıntı olarak tarif edilir (1). Kolonoskopi esnasında kolorektal polipler kolaylıkla tanınır. Poliplerin kolonoskopi ile histopatolojik özelliği hakkında net bir karar vermek zordur. Kolonoskopi esnasında polip çıkarılır ve histopatolojik inceleme yapılarak tam anlamıyla özelliği belirlenmiş olur (2). Polipler \%3-9 oranın karsinomlarla birlikte bulunabilir (3). Kolorektal kanserlerin büyük çoğunluğu poliplerden geliştiği için bu konu önem kazanmaktadır $(3,4)$. Beklenmedik bir klinikle ortaya çıkan ve tanıda yanılmaya neden olan karmaşık dev rektal polipli bir olguyu literatür eşliğinde tartışmak istedik.

\section{OLGU}

Otuz altı yaşında erkek hasta yaklaşık 1 yıldır olan kramp tarzı karın ağrısı ve barsak alışkanlığında bozulma ile dış kuruma başvurmuş. Yapılan tetkiklerde rektum ve çekumda kitleler görülmüş ve biyopsiler alınmış. Her iki kitlenin sonucu iyi diferansiye adenokanser gelmiş. Hasta ileri tetkik ve tedavi amacıyla kliniğimize gönderilmiş. Hastanın anemnezi detaylı alındığında defekasyonla makattan bir yapının dışa sarktığı ve defekasyon sonrası elle içeri ittiği öğrenildi. Rektal dijital muayenede yumuşak kıvamlı, düzgün yüzeyli, mobil ve büyük bir kitle ele geldi. Yapılan kolonoskopik değerlendirmede alt rektumda geniş tabanlı büyük boyutta villöz adenom ve çekumda ülsere vejetan kitle görüldü. Yapılan tüm batın bilgisayarlı tomografi ve Pelvik Magnetik Rezonans görüntülemede rektumun içerisini dolduran yumuşak doku kitleri ve çekumda malign duvar kalınlaşması görüldü (Şekil 1). Rektum duvar kalınlığı normal, perirektal yağlı dokuda patoloji görülmedi. Hastanın rektumdaki kitlesine lokal eksizyon ve çekumdaki kitlesine laparoskopik sağ hemikolektomi

Atıf yapmak için: Çakır M, Kılıç M. Rektal Prolapsusa Neden Olmuş Kanser Görüntüsü Olan Dev Villöz Adenom. Selcuk Med J 2019;35(1): $51-54$ 


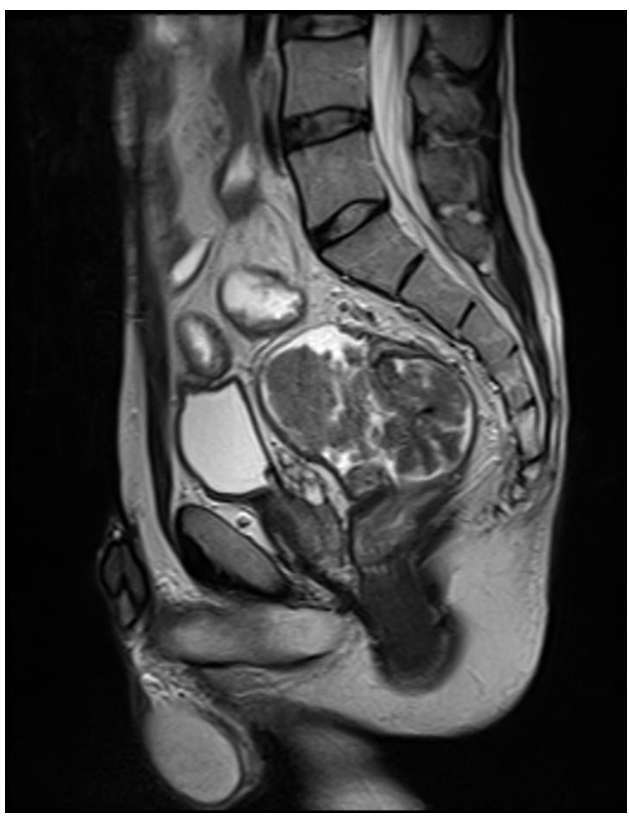

Şekil 1. Olgunun pelvik MR görüntüsü

yapmaya karar verildi. Hasta ameliyat masasında jinekolojik pozisyonda ıkındırılarak kitlenin prolebe olduğu görüldü (Şekil 2). Kitle anal yoldan lokal eksizyon tekniğine uygun olarak eksize edildi (Şekil 3 ). Polibin makroskopik yapısı $14 \times 8 \mathrm{~cm}$ boyutunda, düzgün yüzeyli villöz ademon görünümündeydi. Patolojik inceleme sonrasında çekumdaki kitlenin patoloji sonucu T3N0 olarak geldi. Rektumda insutu kanser içeren villöz adenom olarak geldi. Kanserin lenfovasküler invazyonu yoktu. Rektumdaki villöz adenom için yapılan cerrahi işlemin yeterli olduğuna

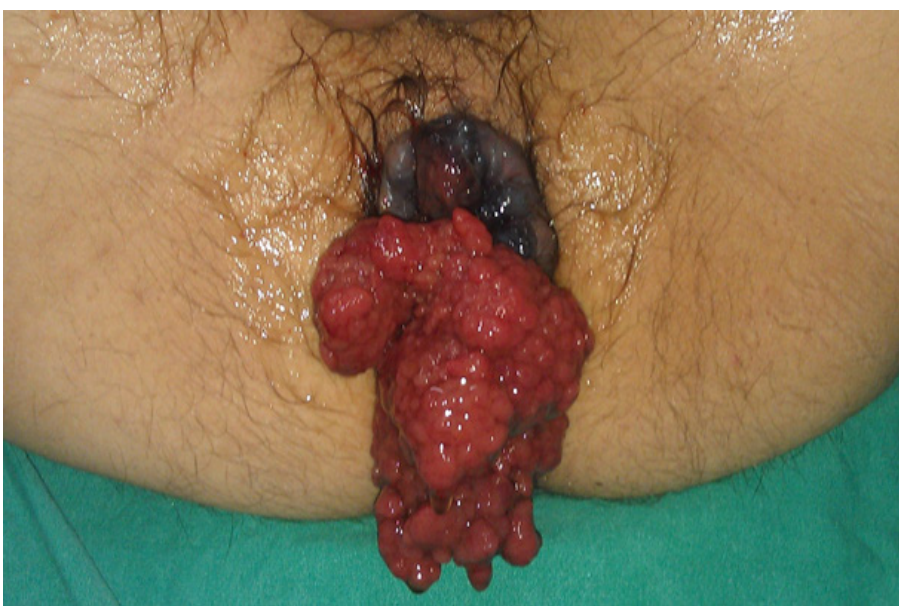

Şekil 2. Prolebe villöz adenom görüntüsü

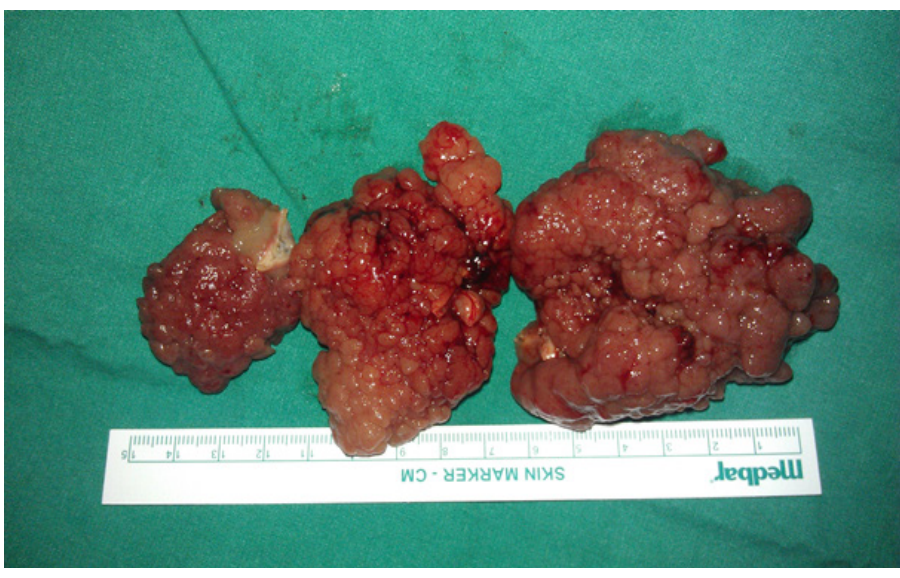

Şekil 3. Cerrahi sonrası piyesin görüntüsü

karar verildi. Salvage cerrahisi uygulanmadı. Hasta tıbbi onkolojiye yönlendirildi.

\section{TARTIŞMA}

Kolorektal poliplerintanısı kolonoskopi, çiftkontrastlı baryumlu kolonografi ve bilgisayarlı kolonografi (sanal kolonoskopi) ile konur. Kolonoskopi sadece tanı amacıyla değil tedavi amacıyla kullanılması ile diğer iki yöntemden ayrılmaktadır. Kliniğimizde rutin olarak kolonoskopi uygulamaktayız. Ancak mükerrer denemelerde çekuma ulaşmayan kolonoskopi girişimleri sonrası çift kontrastlı baryumlu kolonografi istemekteyiz. Böylece proksimal kolon hakkında fikir edinmiş olmaktayız.

Kolonoskopide gördüğümüz polipleri sınıflandırırken göz önünde bulundurduğumuz en önemli iki kriter şekil ve büyüklüktür. Şekillerine göre poliple; pediküllü, sesil, flat ve depresif polipler olarak dört gruba ayrılır. Pediküllü polipler barsağa bir sap kısmı ile tutunur. Bu polipler baş, boyun ve saptan oluşur. Görüntüleri tipiktir ve polipektomisi nispeten sesil poliplere göre daha kolaydır. Sap kısmı olmayan sesil poliplerin tedavisi daha karmaşık ve problemlidir $(5,6)$. Polipler büyüklüklerine göre 3 gruba ayrılır. Altı mm den küçük $(<6 \mathrm{~mm}$ ) polipler ufak (diminutif) polip, $6-10 \mathrm{~mm}$ arasındaki polipler orta büyüklükte polip ve $>10 \mathrm{~mm}$ de büyük polipler büyük boyutlu polipler olarak isimlendirilir. Polibin boyutu arttıkça hem kolonoskopik tedavisi zorlaşır hem de malignite riski artar. Rektumda tespit ettiğimiz polip çok büyüktü. Literatür taramamızda tespit edilen en büyük poliplerden biriydi. Kolonoskopik tedaviye uygun değildi. Bizde lezyonu lokal eksizyonla çıkardık. Kanserin boyutu ile orantılı olarak kanser 
riski arttığından bu hastanın polibinde kanser odağına rastladık.

Önemli olan polibin histopatolojik sınıflamasıdır. Ancak biz bu sınıflamayı kolonoskopi esnasında yapamayız. Çıkardığımız polibin histopatolojik incelemesi sonrasında bu sınıflamayı yapabiliriz. $\mathrm{Bu}$ sonuçla polibin malignite riski ve malignite varlığı belirlenmiş olunur. Klasik sınıflamada polipler histopatolojik olarak 4 grubu ayrılır: Neoplastik polipler (adenomlar), hamartomatöz polipler, inflamatuar polipler ve hiperplastik polipler. Ancak günümüzde bu sınıflama değişmiştir. Artık neoplastik ve nonneoplastik olarak ikiye ayırma tercih edilmekte. Yine de bu sınıflama tartışmalıdır. Özellikle hiperplastik polipler geleneksel sınıflamada nonneoplastik polipler içinde olmasına rağmen artık neoplastik polipler içinde serratid polip alt grubu olarak ifade edilmektedir (7). Serratid polipler malignite potansiyeli taşırlar. Üç grupa ayrılır: Hiperplastik polipler, geneleksel serratid adenomlar, Sessil serratid polipler (sessil serratid adenomlar) $(7,8)$. Hiperplastik poliplerin adenomatöz poliplerden ayırt edilmesi zordur. Histolopatolojik olarak dişli mukozal hücre ile ayrım yapılır. Kolonoskopide tespit ettiğimiz polibin neoplastik adenomatöz bir polip olduğunu gördük.

Adenomatöz polipler kolorektal poliplerin 2/3 ünü oluştururlar. Bu polipler genel nüfusun $\% 5-10$ unda bulunur. Displazi içerirler ve kanser gelişimine neden olurlar. Kolorektal kanserlerin büyük kısmı adenomlarden oluşurken, adenomların \%5'inden azı kansere ilerler (1). İlerlemiş adenom tanımı: $1 \mathrm{~cm}$ den büyük polip, yüksek grade'li displazi ve yoğun villöz komponet içeren adenomları kasteder. Kanser sekansı hızlıdır. Adenomlar \%30-50 oranında senkron adenom taşır (8). Yaş ilerledikçe bulunma sıklığı artar (majör risk faktörü). Adenomların seksenli yaşlarda görülme oranı \%60 lara kadar çıkar $(8,9)$. Polip görülme sıklığı erkeklerde kadınlardan daha fazladırlar (10). Kolorektal polipler ensık rektosigmoid bölgede bulunur. Bu bölgede kolorektal poliplerin \%50'sinden fazlası görülür. Histopatolojik olarak adenomatöz polipler 3 gruba ayrılır (11). Tubuler, tübülovillöz ve villöz adenomlar. Adenom içerisindeki tübül yapısı $\% 75$ den fazla ise tübüler adenom, villöz kompenent $\% 75$ den fazla ise villöz adenom ve tubul yapısı \%25-75 arasındaysa tubulovillöz adenom adını alır. Tübüler adenomlar ensık görülen adenomdur. Tüm kolonda bulunur. Genelde saplı küçük ve düzgun yüzeylidir. Bir $\mathrm{cm}$ den küçük tubuler adenomlarda kanser riski yaklaşık \%5 civarındadır. Tubulovillöz adenomlar \%10-15 oranında bulunur. Çoğunlukla rektum yerleşimlidir. Genelde orta büyüklükte poliplerdir. Malignite riski yaklaşık \%20 kadardır. Villöz adenomlar \% 5 oranında bulunur (12). Genellikle ileri yaştaki hastalarda tespit edilir. Yerleşim yeri genelde rektumdur. Büyük boyutta olur ve sesil yapıdadır. Malignite riski yaklaşık \%40 kadardır. Rektal kanama, mukuslu gayta ve büyük boyutta olanlar anal kanaldan dışa prolebe olabilir. Olgumuz genç olmasına rağmen büyük boyutta polibi vardı. Çıkarılan polibin kanser içerdiğini gördük.

Polipektomi sonrası histopatolojik olarak kanser tanımlanan hastalarda cerrahi kararı vermek için bakılması gereken en önemli kriterler polipektomi sınırıdır. Kabul edilebilir cerrahi sınır en az $2 \mathrm{~mm}$ olmasıdır. Cerrahi sınır $2 \mathrm{~mm}$ den az, histopatolojik incelemede lenfovasküler invazyon ve indiferansiye kanser varlığı, parçalı polipektomi ve hastanın genel durumu iyi ise cerrahi yapılmalıdır. İnvaziv kanser içeren polipektomilerde lenf nodu tutulum oranı \%9 lara kadar çıkmaktadır. Risk lezyonun tipine göre değişir. Sapsız polipte bu oran \%15 kadardır. Saplı polipte ise bu oran daha düşüktür. Karsinom polipin sadece baş kısmında ise lenf nodu tutulumu daha düşük iken sap kısmında ise bu oran çok daha yüksektir. Saplı poliplerde Haggitt sınıflaması (13), sapsız poliplerde Kudo sınıflaması (14) cerrahi kararda yardımcı olmaktadır. Kanser riski taşıyan polipektomilerde polipektomi yeri işaretlenmelidir. Kanserin polipektomi yerinin $2 \mathrm{~mm}$ daha uzak olması, iyi diferansiye, lenfovasküler invazyon olmaması nedeniyle tekrar cerrahi işlem uygulamadık.

Sonuç olarak kolorektal polipler kanser riski taşıyan lezyonlar olduğu için detaylı histopatolojik inceleme yapılmalı ve cerrahi karar titizlikle verilmelidir.

Çıkar Çatışması: Çalışmada herhangi bir çıkar çatışması yoktur.

Finansal Çıkar Çatışması: Çalışmada herhangi bir finansal çıkar çatışması yoktur.

Yazışma Adresi: Murat Çakır, Necmettin Erbakan Üniversitesi Meram Tıp Fakültesi Genel Cerrahi servisi Akyokuş/Meram/ Konya, Türkiye. Posta kodu: 42080

E-mail: drmuratcakir@hotmail.com Tel: 03322236395

\section{KAYNAKLAR}

1. Heitman SJ, Ronksley PE, Hilsden RJ, et al. Prevalence of adenomas and colorectal cancer in average risk individuals: A systematic review and meta-analysis. Clin Gastroenterol Hepatol 2009;7(12):1272-6.

2. Soetikno R, Friedland S, Kaltenbach T, et al. Nonpolypoid (flat and depressed) colorectal neoplasms. Gastroenterology 2006;130(2):566-72.

3. The Paris endoscopic classification of superficial neoplastic 
lesions: Esophagus, stomach, and colon: November 30 to December 1, 2002. Gastrointest Endosc 2003;58:S3-43-6.

4. Arain MA, Sawhney M, Sheikh S, et al. CIMP status of interval colon cancers: Another piece to the puzzle. Am J Gastroenterol 2010;105(5):1189-95.

5. Laiyemo AO, Murphy G, Sansbury LB, et al. Hyperplastic polyps and the risk of adenoma recurrence in the polyp prevention trial. Clin Gastroenterol Hepatol 2009;7(2):192-7.

6. Soetikno RM, Kaltenbach T, Rouse RV, et al. Prevalence of nonpolypoid (flat and depressed) colorectal neoplasms in asymptomatic and symptomatic adults. JAMA 2008;299(9):1027-31.

7. Rex DK, Ahnen DJ, Baron JA, et al. Serrated lesions of the colorectum: Review and recommendations from an expert panel. Am J Gastroenterol 2012;107(9):1315.

8. Carlsson G, Petrelli NJ, Nava $H$, et al. The value of colonoscopic surveillance after curative resection for colorectal cancer or synchronous adenomatous polyps. Arch Surg 1987;122(11):1261-6.

9. Williams AR, Balasooriya BA, Day DW. Polyps and cancer of the large bowel: A necropsy study in Liverpool. Gut 1982;23(10):835-9.
10. Ben $Q, A n W$, Jiang $Y$, et al. Body mass index increases risk for colorectal adenomas based on meta-analysis. Gastroenterology 2012;142(4):762-7.

11. O'Brien MJ, Winawer SJ, Zauber AG, et al. The National Polyp Study. Patient and polyp characteristics associated with highgrade dysplasia in colorectal adenomas. Gastroenterology 1990;98(2):371-7.

12. Atkin WS, Saunders BP. British Society for Gastroenterology, Association of Coloproctology for Great Britain and Ireland. Surveillance guidelines after removal of colorectal adenomatous polyps. Gut 2002;51:6-11.

13. Riddell RH, Goldman H, Ransohoff DF, et al. Dysplasia in inflammatory bowel disease: Standardized classification with provisional clinical applications. Hum Pathol 1983;14(11):93168.

14. Kudo SE, Wakamura K, Ikehara N, et al. Diagnosis of colorectal lesions with a novel endocytoscopic classification - a pilot study. Endoscopy 2011;43(10):869-75. 